\title{
Catenotaenia dendritica (Cestoda: Catenotaeniidae) and Three Ectoparasite Species in the Red Squirrel, Sciurus vulgaris, from Cheongju, Korea
}

\author{
Seongjun Choe', Dongmin Lee', Hansol Park', Hyeong-Kyu Jeon'1, Youngsun Lee², Ki-Jeong Na, ${ }^{2,3}$ In-Yong Lee \\ Keeseon S. Eom ${ }^{1, *}$ \\ ${ }^{1}$ Department of Parasitology, Medical Research Institute and Parasite Resource Bank, School of Medicine, Chungbuk National University, \\ Cheongju 28644, Korea; ${ }^{2}$ The Wildlife Center of Chungbuk, Cheongju 28116, Korea; ${ }^{3} \mathrm{College} \mathrm{of} \mathrm{Veterinary} \mathrm{Medicine,} \mathrm{Chungbuk} \mathrm{National} \mathrm{University,}$ \\ Cheongju 28644, Korea; ' 4 Department of Environmental Medical Biology and Institute of Tropical Medicine, Yonsei University College of Medicine, \\ Seoul 03722, Korea
}

\begin{abstract}
Parasites are recorded from the red squirrel, Sciurus vulgaris, from Cheongju, the Republic of Korea. A total of 5 road-killed squirrels were thoroughly examined for internal and external parasites from November 2011 to May 2014. Total 4 parasite species, including 1 tapeworm and 3 ectoparasite species were recovered. They were morphologically identified as Catenotaenia dendritica (Cestoda: Catenotaeniidae), Hirstionyssus sciurinus, Leptotrombidium pallidum, and Ceratophyllus (Monopsyllus) indages. Among them, $\mathrm{C}$. dendritica and $\mathrm{H}$. sciurinus are recorded for the first time in the Korean parasite fauna. In addition, the possibility that the red squirrel could act as a reservoir host for a zoonotic disease like tsutsugamushi disease with $L$. pallidum as its vector has been raised.
\end{abstract}

Key words: Sciurus vulgaris, Catenotaenia dendritica, Hirstionyssus sciurinus, Leptotrombidium pallidum, Cetatophyllus (Monopsyllus) indages, red squirrel, Cheongju, Korea

\section{INTRODUCTION}

The red squirrel, Sciurus vulgaris Linnaeus, 1758, is a sciurid rodent that is distributed widely in Europe and the Palearctic region of Asia. This species of rodent mainly inhabits in the forest regions with coniferous trees and sometimes comes out in mixed woodlands bearing the food materials. It has been known that the red squirrels prefer eating some kinds of seeds, berries, fruits, and fungi. However, when these main foods are unavailable, they eat alternative foods, even animals [1].

In the Republic of Korea (Korea), the red squirrel is distributed in a wide range of forests in the Peninsula and Jeju-do (Island) [2]. This species recently became one of the most visible wildlife in Korea as a result of the absence of predators and fragmentation of its native habitats. It is frequently observed in areas of human activity, including parks, orchards, and univer-

\footnotetext{
- Revised 16 December 2015, revised 15 May 2016, accepted 8 June 2016.

*Corresponding author (kseom@chungbuk.ac.kr)

(C) 2016, Korean Society for Parasitology and Tropical Medicine

This is an Open Access article distributed under the terms of the Creative Commons Attribution Non-Commercial License (http://creativecommons.org/licenses/by-nc/4.0) which permits unrestricted non-commercial use, distribution, and reproduction in any medium, provided the original work is properly cited.
}

sity campuses (personal communication). The increased human contact with this species has potentiated the sharing of pathogens. This possibility indicates the need for investigations on the parasitic fauna of the red squirrel in Korea. To date, the only parasites recorded in red squirrels in Korea are the flea species Ceratophyllus (Monopsyllus) indages and 3 species of mites, Hirstionyssus carnifex, Neotrombicula ichikawai, and Zumptiella coreaensis [3-5].

During our survey of the parasitic fauna in Korean wildlife, we had the opportunity to examine Korean red squirrels. We recovered 1 species of tapeworm and 3 species of ectoparasites from road-killed squirrels. In the present study, we described them based on the morphological characteristics in the faunistic view points.

\section{MATERIALS AND METHODS}

Five carcasses of the red squirrel were found on the road in the campus of Chungbuk National University, Cheongju-si (city), Chungcheongbuk-do (province) (= Chungbuk), Korea between November 2011 and May 2014. The carcasses were bleeding when they were found. All seemed to be road kills. 
They first underwent physical examinations by veterinarians at the Wildlife Center of Chungbuk. Thereafter, the carcasses were individually stored in plastic bags and transferred to the Parasite Resource Bank of Korea for parasitological examinations. One of the carcasses was a juvenile; the remainders were adults. The genders of the squirrels were not checked. Before necropsy, the carcasses were hung above a bowl of water for 2 $\mathrm{hr}$ to collect ectoparasites. Thereafter, all visceral organs were examined for the presence of endoparasites.

All retrieved ectoparasites, including fleas and mites, were fixed with $70 \%$ ethyl alcohol. For morphological examinations, the fleas were cleared in potassium hydroxide for $24 \mathrm{hr}$ and mounted with polyvinyl alcohol. Small mites were mounted with polyvinyl alcohol or Hoyer's medium. The visceral organs of the squirrels were dissected and washed in warm water. Three tapeworms were retrieved. All were transferred to $0.85 \%$ saline and fragmented for identification. For the morphological examination, 2 worms were unrolled on the slide glass with applicators and fixed on the slide glass with hot $10 \%$ formalin solution without pressure. They were stained with Semichon's acetocarmine, decolored with HCl-alcohol, and dehydrated using an alcohol series $(50 \%, 70 \%$, $80 \%, 90 \%, 95 \%, 100 \%$, and again 100\% ethyl alcohol; $30 \mathrm{~min}$ per step). After clearing with xylene, the worms were mounted with Permount. The worms then underwent morphometric measurements (given in $\mu \mathrm{m}$ ) according to the method described by Haukisalmi [6]. Scanning electron microscopy (SEM) was used to obtain an apical view of the scolex.

\section{RESULTS}

\section{Recovery of parasites}

Four species of parasites were collected from the red squirrels. Three were ectoparasites, and 1 was a cestode species found in the small intestine. The tapeworm was found in 2 of the 5 red squirrels. The ectoparasites were initially identified as mesostigmatid mites, chigger mites, and fleas on the basis of their general morphology and the position of the spiracle. The infection rates were not calculated because the carcasses were collected sporadically. Detailed information of collection is provided in Table 1.

\section{Faunistic record of Catenotaenia dendritica Goeze, 1782}

Three sets of fully grown tapeworm specimens were collected from 2 squirrels. Strobilae were long and thin, and retained a full set of proglottids, including the scolex and neck. Each proglottid was longer than wide. The scolex was small and simple with 4 oval-shaped lateral suckers and a small apical sucker on a slightly elevated rostellum (Figs. 1A, 2). The rostellum was poorly developed or obscured. The neck was clearly distinguished from the scolex. The mature and gravid proglottids were usually uniformly shaped, craspedote, and widest at the genital pore. The genital pore was located at the anterior region of the middle third of the proglottid and opened at the side of the proglottids in a random fashion. There was anterior free space on the mature proglottids that separated the ovary from the anterior margin of the proglottids. The ovary was asymmetrical and comparatively short (45-50\%). It was composed of vimineous lobular structures that were distributed to the anterior half. One side was filled posteriorly from the genital pore, and its opposite side was filled posteriorly from the mid-level of the vitellarium. Both sides reached anteriorly to the anterior free space. The ovary was restricted medially by longitudinal canals. The vitellarium was lobulated, a little bit bolder than the ovary, and located posteriorly to the side at which the genital pore was located. The testicular field filled the posterior half of the proglottids. There were 133-178 testes, and they slightly overlapped with the posterior region of the ovary and vitellarium. The testicular field was divided longitudinally. The 2 halves overlapped partially. The testes were small, round, and strewn over the testicular field (Fig. 1C). The cirrus sac lay transversely or slightly obliquely. The vas deferens

Table 1. Parasites found in red squirrels Sciurus vulgaris in the present study

\begin{tabular}{lccccc}
\hline \multirow{2}{*}{ Host code No. } & Date & \multicolumn{2}{c}{ Parasite species } \\
\cline { 3 - 6 } & & Catenotaenia dendritica & Hirstionyssus sciuruinus & Leptotrombidium pallidum & Ceratophyllus (Monopsyllus) indages \\
\hline B408 & 2011.11 & 2 & - & 26 \\
B507 & 2012.05 & - & - & - & - \\
B513 & 2012.05 & - & - & - & - \\
B906 & 2014.03 & 1 & 18 & - \\
B937 & 2014.05 & - & 14 \\
\hline
\end{tabular}




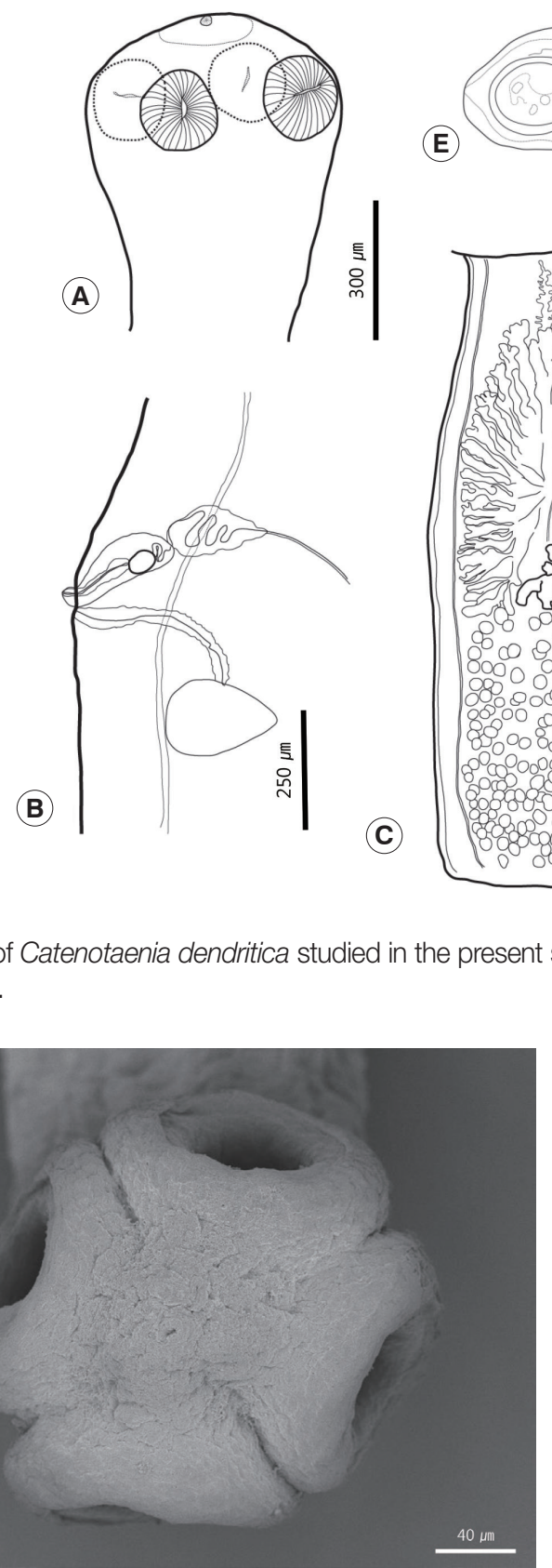

Fig. 2. Apical view of the scolex of Catenotaenia dendritica.

was slightly convoluted. The vagina was slightly curved and opened posteriorly to the cirrus pore. A thick cell layer surrounded the vagina. The seminal receptacle was located slightly behind the genital pore and anteriorly of Mehlis' gland (Fig. 1B). The gravid proglottids were elongated and had a larger length/width ratio than the mature proglottids. The uterus possessed 31-39 primary branches on each side. Secondary branches were present (Fig. 1D). The eggs collected from uter- us were caudated, 43-50 $(\mathrm{n}=35)$ by 20-25 (24) (Fig. 1E). The morphometric measurements of the cestodes reported in this study are shown in Table 2.

\section{Faunistic record of Hirstionyssus sciurinus (Hirst, 1921)}

Hirstionyssus sciurinus (Hirst, 1921) is a mesostigmata mite that belongs to the family Laelapidae Berlese, 1892. Six female mites were recovered from the squirrel no. B0937. The body of the female mite was 686-764 (average 727) long and the maximum width was 323-510 (441). The dorsal shield had a subhexagonal shape with a parallel lateral border and triangular caudal border (Figs. 3A, 4A). The dorsal shield was covered with 26 pairs of dorsal setae. The dorsal setae were usually very short, but the setae near the anterior margin of the dorsal plate were slightly longer than the medial dorsal setae (Fig. 4A). The sternal shield and genitoventral shield were present on ventral region (Fig. 3B). The sternal shield had a subrectangular shape and bore 3 pairs of setae. The posterior margin was slightly concave. The sternal shield was 55-67 (59) long and 97-139 (113) wide. Sternal setae 1 (st1) were shorter than the length of the sternal plate (Fig. 3C). Genitoventral shield was 107-122 (114) long and 77-82 (79) wide, and was shaped like a tongue 
Table 2. Comparison of Catenotaenia spp. morphometrics with those of previous studies

\begin{tabular}{|c|c|c|c|}
\hline & $\begin{array}{c}\text { Catenotaenia dendritica } \\
\text { Present study }\end{array}$ & $\begin{array}{l}\text { Catenotaenia dendritica } \\
\text { Haukisalmi et al. } 2010\end{array}$ & $\begin{array}{l}\text { Catenotaenia ris } \\
\text { Yamaguti } 1942\end{array}$ \\
\hline Body length (mm) & 98-171 & $81-208$ & $>120$ \\
\hline Scolex L & 395 & & \\
\hline Scolex W & 356 & $290-350$ & $270-330$ \\
\hline Sucker L & $125-138(113)$ & & $110-160$ \\
\hline Sucker W & $110-120(116)$ & & $105-160$ \\
\hline Neck L & 593 & & $750-1,750$ \\
\hline Neck W & 227 & & $140-210$ \\
\hline Mature prog. L & $2,800-4,200(3,470)$ & & $2,000-5,600$ \\
\hline Mature prog. W & $1,188-1,500(1,319)$ & & $450-1,500$ \\
\hline Vitelling field $L$ & $400-825$ (592) & & 350 \\
\hline Vitelling field W & $375-550(475)$ & & 300 \\
\hline Ovary L & $1,325-2,000(1,638)$ & & \\
\hline Ovary W & $725-875$ (792) & & \\
\hline Testis field $\mathrm{L}$ & $1,125-1,625(1,321)$ & & \\
\hline Testis field W & $750-1,075(867)$ & & \\
\hline Testis number & 133- $178(152)$ & $140-233$ & $140-190$ \\
\hline Gravid prog. L & $6,150-9,250(7,415)$ & & $2,200-8,000$ \\
\hline Gravid prog. W & $1,400-1,825(1,665)$ & $1,300-1,800$ & $700-2,500$ \\
\hline Number of uterine branches & $31-39(35)$ & $35-60$ & $30-40$ \\
\hline Egg L & $43-50(46)$ & $18-33$ & $18-33$ \\
\hline Egg W & $20-25(24)$ & & $16-30$ \\
\hline
\end{tabular}

L, Length; W, Width.
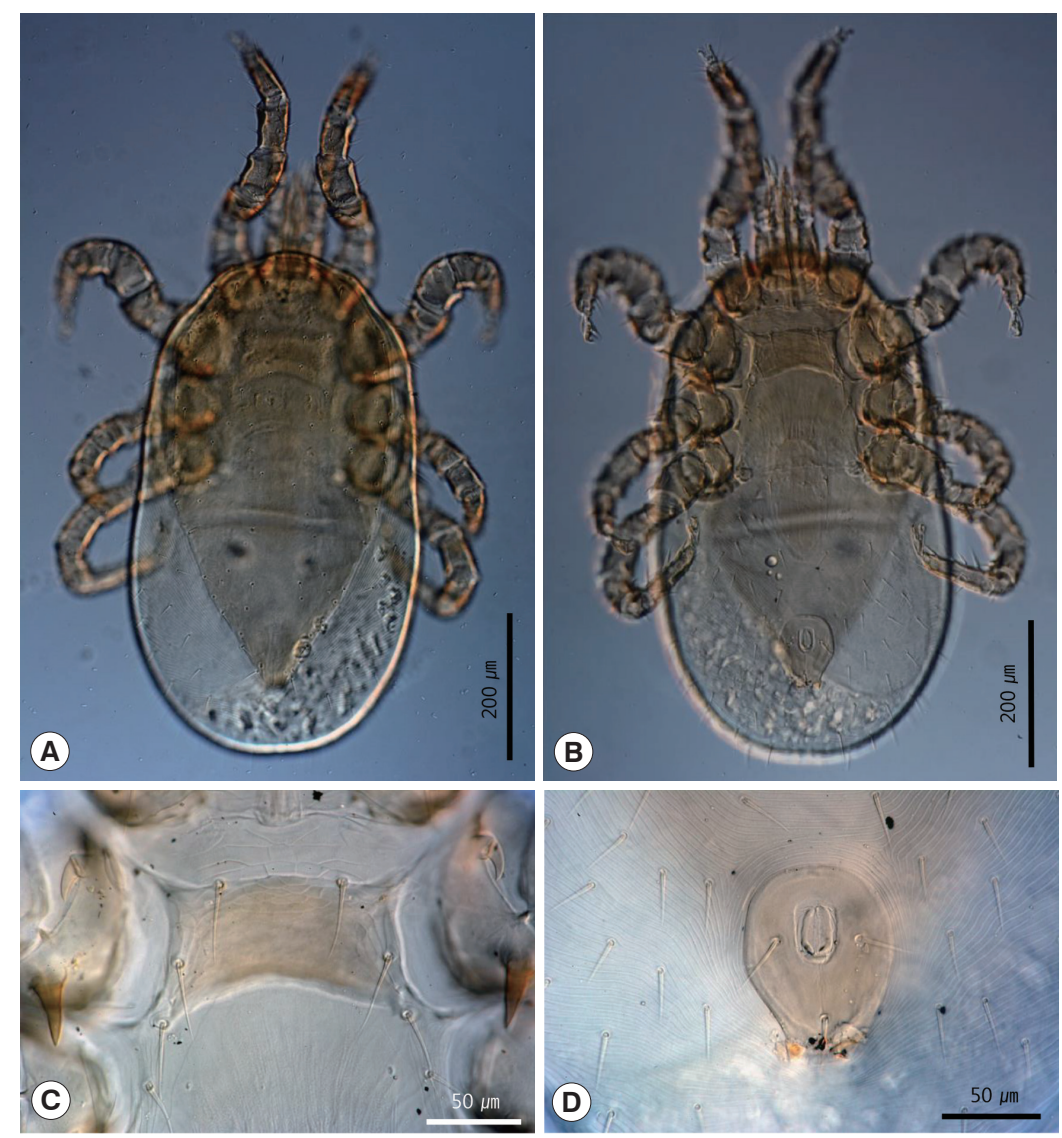

Fig. 3. Female Hirstionyssus sciurinus recovered in the present study. (A) Whole body, dorsal view. (B) Ventral view. (C) Sternal plate. (D) Genitoventral shield. 


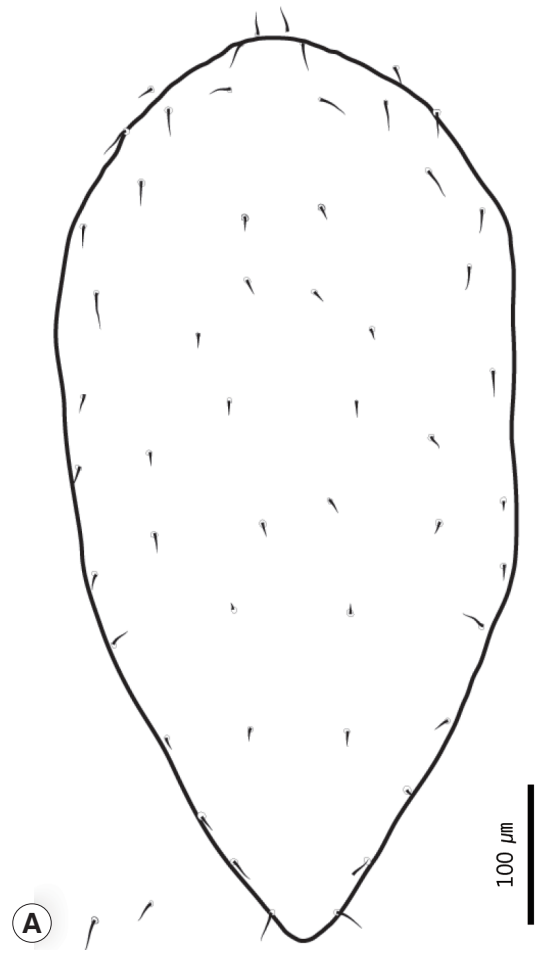

(B)

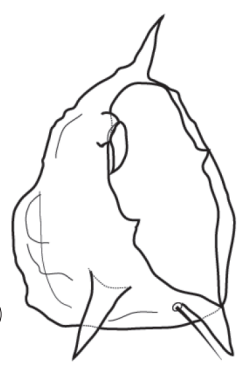

(C)

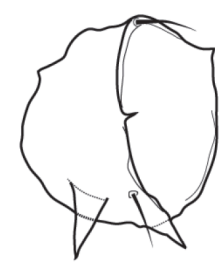

(D)

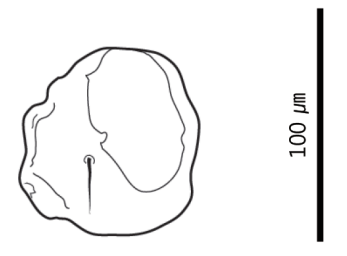

Fig. 4. Drawings of Hirstionyssus sciurinus. (A) Dorsal plate and setae. (B) Coxa II. (C) Coxa III. (D) Coxa IV.
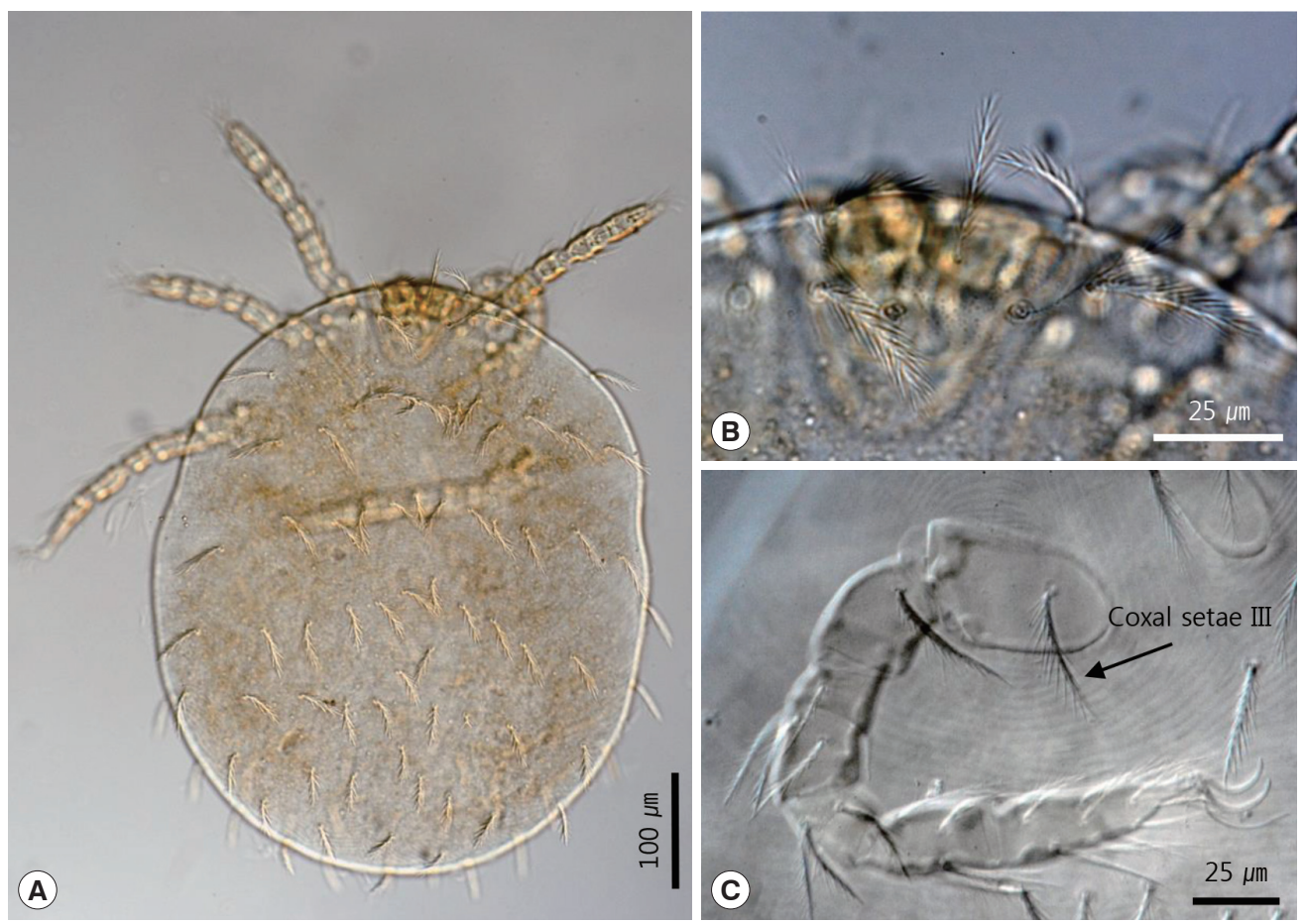

Fig. 5. Larva of Leptotrombidium pallidum. (A) Whole body, dorsal view. (B) Scutum. (C) Coxal seta III separated from the anterior margin of the coxa III.

and had a pair of para-anal setae and 1 post-anal seta (Fig. 3D). Coxa I was unarmed. Coxa II was armed with 1 anterior and 2 posterior spurs. The anterior seta of coxa II was modified into a strong spur-like seta. The posterior seta of coxa II 


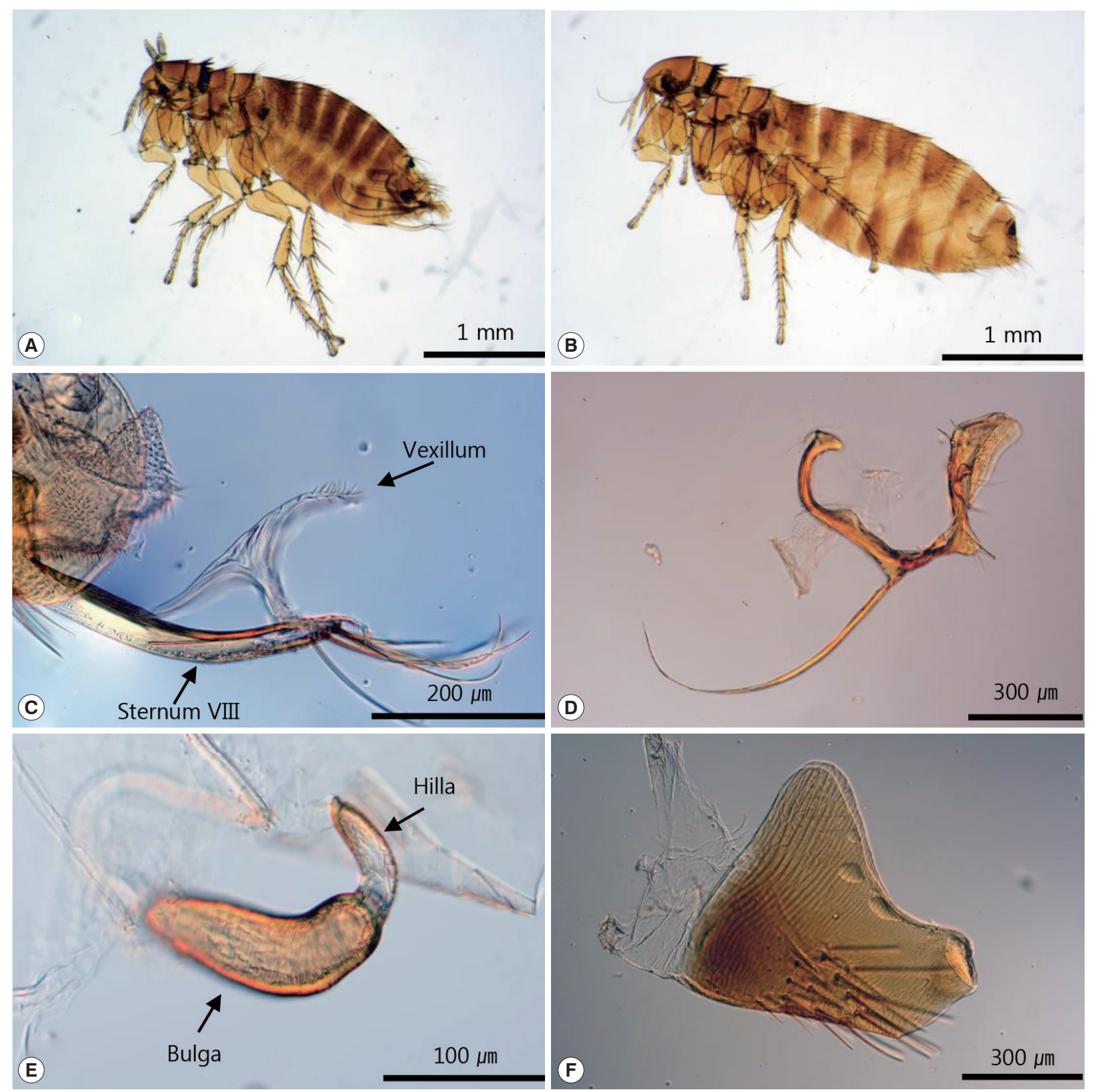

Fig. 6. Ceratophyllus (Monopsyllus) indages. (A) Male. (B) Female. (C) The pickax-shaped vexillum on the male sternum VIII. (D) Expanded tip of the male sternum IX. (E) Spermatheca. (F) Typical shape of sternum VII of a female.

was thinner and longer than the anterior seta (Fig. 4B). Coxa III was armed with 2 robust posterior spurs and 2 setae. The anterior seta was located at the anterior extremity of coxa III. The posterior seta was between 2 spurs (Fig. 4C). Coxa IV was simple with a small seta (Fig. 4D). The total coxal spur formula was $0-3_{(1+2)-}-2_{(0+2)}-0$ (Fig. 4B-D). The setae of tarsus II were needle shaped.

\section{Identification of Leptotrombidium pallidum and Ceratophyllus (Monopsyllus) indages}

With regard to the chigger mites we identified, we collected 26 of these mites from no. B0408. All specimens were larvae with 3 pairs of legs (Fig. 5A). The scutum was rectangular with 1 anteromedian seta, 4 setae on each angle, and 1 pairs of median setae on each side of the scutum plane (Fig. 5B). The setae were basally barbed. Coxal seta III was located on the anteromedian region of coxa III (Fig. 5C). In addition, there were 
also 14 setae on the first row of posthumeral setae (Fig. 5A). Total 33 fleas were collected. The pronotal comb was present, but the genal comb was absent (Fig. 6A, B). The male flea (Fig. $6 \mathrm{~A})$ had the typical pickax-shaped vexillum on the long and narrow sternum VIII (Fig. 6C), and the tip of sternum IX was expanded (Fig. 6D). The female flea (Fig. 6B) had a spermatheca with a longer bulga (Fig. 6E). Sternum VII of the female was long, and the ventral margin was slightly angulated dorsally. The posterior margin was inclined and somewhat formed an arch distally. The dorsocaudal part of the margin was angulated dorsally and re-inclined (Fig. 6F).

\section{DISCUSSION}

Until now, only 3 species of mites and a flea species were reported from red squirrels in Korea [3-5]. In this study, we found 3 species of ectoparasites and a species of tapeworm. With the exception of $C$. (Monopsyllus) indages, 3 other species (C. dendritica, H. sciurinus, and L. pallidum) were firstly detected from the red squirrel in Korea.

Catenotaenia tapeworms are parasites of various rodents that belong to 3 suborders (Myomorpha, Sciuromorpha, and Castorimorpha) [6]. Haukisalmi et al. [6] provided a taxonomical review of the genus Catenotaenia in Eurasia; they sought to distinguish each species using morphological characteristics, including the outline shape of the segments and 28s rRNA sequencing. According to their review, our specimens appear morphologically similar to $C$. dendritica. C. dendritica is known to be a host-specific parasite of $S$. vulgaris, and, indeed, our specimens were recovered from this host. This species has several distinct characteristics compared with other Catenotaenia species. First, the proglottids are elongated and have an almost uniform width. Second, there are numerous uterine branches. Third, the testicular field is divided longitudinally [6]. In addition, as reported by Joeux and Baer [7], C. dendritica has elongated proglottids, and the length/width ratio; the mature and gravid proglottids are 4 and 8 times longer than the width of the proglottid, respectively. Spaskii [8] also noted that the proglottid width varied very little; he termed it as 'almost constant'. Moreover, he considered the longitudinal division of the testicular field and the number of testes $(<300)$ to be key features of this species [8]. Haukisalmi et al. [6] also suggested additional diagnostic characteristics, namely, the presence of the anterior free space, comparatively short ovary $(<40 \%)$, antero-poral merging of the seminal receptacle and vagina, and position of the seminal receptacle (positioned anterior to the Mehlis' gland). All of these morphological features were also observed in our specimens.

However, our specimens also matched to the description of Catenotaenia ris Yamaguti, 1942. Yamaguti [9] obtained several specimens from the small intestine of Sciurus lis Temminck from Nagano Prefecture, Japan and named the species Catenotaenia ris. He found that his species differed from $C$. dendritica in that its apical sucker was small relative to the 4 lateral suckers, and there were fewer testes [9]. In relation to the number of testes, Yamaguti [9] reported 140-190 testes in C. ris, whereas Riggenbach [10] reported that $C$. dendritica had 200-210 testes. However, when Joyeux and Baer [7] re-observed the Riggenbach's material, they found that the real number of testes was 140-190. Our specimens had 133-178 testes. In addition, Joyeux and Baer [7] described the degeneration of the apical sucker in adult Catenotaenia pusilla (Goeze, 1782), although it appeared to be functional in metacestodes. On the basis of these observations, they considered $C$. ris as a synonym of $C$. dendritica [7]. This conclusion was supported by Spasskii [6] and Haukisalmi et al. [8]. This suggests that our specimens are indeed $C$. dendritica. However, it should be noted that the morphometric data of $C$. dendritica provided by Haukisalmi et al. [6] exhibit considerable variation, especially in terms of the number of testes (130-233) and uterine branches (35-60). This suggests that either their data were from at least 2 different species or their data included erroneous data, similar to the case of Riggenbach [7]. In any case, we considered our specimens to be $C$. dendritica at this time, but this conclusion is tentative and will have to be confirmed by additional molecular analysis and comparison with the known sequences of $C$. dendritica [6].

Unfortunately, we could not collect male mesostigmatid mites. Thus, our morphological observations were based on female specimens only. However, this seems sufficient for identifying the species. Three species of Hirstionyssus mites are known to distribute in Korea, namely, H. isabellinus (Oudemans, 1913), H. sunci Wang, 1962 (=H. apodemi Zuevsky, 1970), and H. carnifex (Koch, 1829) [4,11,12]. Kim et al. [11] also found males, females, and deutonymphs of mesostigmatid mites in Rattus norvegicus and Apodemus agrarius, and identified these as H. apodemi. However, Uchikawa [13] concluded that $H$. apodemi is a synonym of $H$. sunci after observing the morphological variation of the sternal shield. This conclusion was supported by Mašán and Fenda [14]. We also agree with 
this conclusion and thus call this species H. sunci in the present report. However, our specimens did not match the descriptions of the 3 Hirstionyssus mite species reported previously in Korea $[11,12]$. Unlike these Hirstionyssus mites, our specimens had a tapered subhexagonal dorsal shield and a sternal shield that was longer than st1. Although Hirstionyssus carnifex also has a subhexagonal dorsal shield, the posterior region of its shield is wider than the anterior region [14]. Its sternal shield also looks similar to that in our specimens, but it is wider. Hirstionyssus sunci and Hirstionyssus isabellinus differ from our specimens by having a suboval-shaped dorsal shield and a longitudinally narrow sternal shield because of the curved posterior margin. In particular, our specimens differed from these 3 Hirstionyssus mite species most markedly in their coxal spur formula; it was 0-3-2-0 in our specimens, whereas it is $0-2_{(1+1)-2} 2_{(0+2)}-0$ in $H$. isabellinus, $0-2_{(1+1)-2} 2_{(0+2)}-1_{(0+1)}$ in H. carnifex, and $0-2_{(1+1)-2} 2_{(0+2)}-1_{(0+1)}$ in $H$. sunci [14]. Thus, on the basis of these morphological differences, we conclude that our specimens are a previously unrecorded mite species in Korea. Instead, it is likely that our specimens belong to H. sciurinus since the morphological characteristics of our specimens perfectly match those of $H$. sciurinus from Slovakia [14] and the original description [15]. Since this species is also known to be a parasite of the red squirrel in Slovakia $[14,16]$, we regard our specimens as being $H$. sciurinus.

Comparison with the previously suggested key for the chigger mites [17] indicated that these characteristics were sufficient to identify our specimens as L. pallidum. This species is known to be a predominant species in small mammals from the northern part of Korea [18-20]. Several records indicated that larval $L$. pallidum has a variety of hosts [3,18-21]. However, the red squirrel has not been reported previously to be a host for this ectoparasite, although there is a report that chigger mites (including L. pallidum) have been found in S. v. lis in Japan [22]. Thus, the present study suggests that the red squirrel may be another host of chigger mites in Korea.

In the present study, fleas were the most dominant ectoparasites of the red squirrels. Only 1 species, C. (Monopsyllus) indages, has been reported in red squirrels in Korea [4]. The specimens in our study also had all the morphological characteristics of $C$. (Monopsyllus) indages that were described previously $[23,24]$. The species was first reported by Rothschild [23] on the basis of the morphology of female fleas collected from $S$. vulgaris orientalis in Hokkaido, Japan.

Of the parasite species investigated in the present study, $C$. dendritica seems to be the least important in terms of human health whereas arthropod parasites may cause health problems. Many fleas are known to lack strict host selection, and this means that fleas can readily act as vectors of zoonotic diseases [25]. In addition, several human cases of rat mite dermatitis caused by the mesostigmatid mite Ornithonyssus bacoti have been reported in Korea [26]. It is unclear whether $\mathrm{H}$. sciurinus can bite humans. However, it is quite possible that it, like other mite species, can act as an allergen. In the case of chigger mites, L. pallidum is known to be a vector of tsutsugamushi disease in Korea, which is caused by Orientia tsutsugamushi: this was proven by Rhee et al. [27] who found by an indirect fluorescent antibody test that 2 of 447 individual L. pallidum collected in Korea bore Orientia tsutsugamushi. Although we did not try to identify the pathogens in either our specimens or the hosts, the fact that our red squirrels carried L. pallidum suggests that the red squirrel in Korea could potentially act as a reservoir host for tsutsugamushi disease. Although ectoparasite infection in Korea is generally regarded as an occupational infection of farmers or people who associate with fields, our results suggest that ectoparasites may be unexpectedly close to the sidewalks and lawns that are frequently used by people. Thus, caution may be needed when people undertake outdoor activities in places that are inhabited by animals like the red squirrel, even university campuses.

Compared with the previously reported parasitic fauna of red squirrels, our squirrels had relatively poor parasitic species diversity. Feliu [28] found 5 species of helminths in 248 S. vulgaris from the Iberian Peninsula, namely, C. dendritica, Trichostrongylus retortaeformis, Mastophorus muris, Syphabulea mascomai, and Rodentoxyuris sciuri. Moreover, Shimalov and Shimalov [29] found 11 species of helminths in 30 adult specimens of S. vulgaris in Belorussian Polesie. Cyprich et al. [16] recorded 19 ectoparasite species in 93 S. vulgaris specimens and 32 nests in Slovakia. Although some of the species were considered occasional infections, the species variety was larger than that in our squirrels. Romeo et al. [30] found 5 species of nematodes and 13 specimens of unidentified cestodes in 147 red squirrels; they also found 7 species of ectoparasites in 311 squirrels [30]. We only found 1 tapeworm and 3 species of ectoparasites. Moreover, we could not find any of the previously reported mite species of $S$. vulgaris in Korea [3,5]. There are several possible reasons for this. First, Romeo et al. [30] suggested that the macro-parasitic fauna of red squirrels may be mainly composed of parasites that have direct life cycles be- 
cause the red squirrel is an independent animal that spends almost all of its time in trees [31]. The poor species diversity that we observed may also reflect habitat fragmentation. The study area was surrounded by broad roads that isolated the area from other red squirrel habitats such as mountains and woodlands. In addition, the red squirrel population in the area had been estimated to include fewer than 30 individuals (personal communications). This environmental isolation may interrupt the exchange of parasites between individuals and also other populations, and even other species. In addition, carnivores and ungulates are absent in the area or clearly rare. The absence of these kinds of animals could decrease the chance that the squirrels become infested with ticks or species of helminths that use these animals as the final host. Moreover, present study has a limitation of collecting ectoparasites because they tend to escape from its host when the host is dead. Therefore, to improve our understanding of the parasitic fauna of the red squirrels and their ecology in Korea, further studies are needed with animals collected from well-preserved natural environments.

In conclusion, the present study investigated the parasitic fauna of red squirrels in a university campus in Korea. We added 2 previously unrecorded species, $C$. dendritica and $H$. sciurinus to the Korean taxa and showed that the red squirrels may carry ectoparasites of public health importance.

\section{ACKNOWLEDGMENTS}

This work was supported by a grant from the National Institute of Biological Resources (NIBR), which is funded by the Ministry of Environment (MOE) of the Republic of Korea. One of the authors (Seongjun Choe) was supported by Graduate Program for the Undiscovered Taxa of Korea (NIBR201524202). The parasite materials used in this study were provided by the Parasite Resource Bank of Korea of the National Research Resource Center (2012-0000037) of the Republic of Korea.

\section{CONFLICT OF INTEREST}

We have no conflict of interest related to this work.

\section{REFERENCES}

1. Lurz PWW, Gurnell J, Magris L. Sciurus vulgaris. American Society of Mammalogists. Mammalian Species 2005: 769; 1-10.
2. Jo YS, Kim TW, Choi BJ, Oh HS. Current status of terrestrial mammals on Jeju Island. J Species Res 2012; 1: 249-256.

3. Southwick JW, Ectoparasite survey of South Korea. Progress Report of 5th Preventive Medicine Unit 65th Medical Group FASCON. 1968, p 117.

4. Tipton VJ, Southwick JW, Ah HS, Yu HS. Fleas of Korea. Korean J Parasitol 1972; 10: 52-63.

5. Ah HS. Zumptiella coreaensis, a new species of nasal mite from the Korean squirrel, Sciurus vulgaris coreae Sowerby, 1921. Parasitology 1964; 54: 403-408.

6. Haukisalmi V, Hardman LM, Henttonen H. Taxonomic review of cestodes of the genus Catenotaenia Janicki, 1904 in Eurasia and molecular phylogeny of the Catenotaeniidae (Cyclophyllidea). Zootaxa 2010; 2489: 1-33.

7. Joyeux C, Baer JG. Morphologie, évolution et position systématique de Catenotaenia pusilla (Goeze, 1782) cestode parasite de rongeurs. Revue Suisse Zool 1945; 52: 13-51.

8. Spasskii AA. Anoplocephalate tapeworms of domestic and wild animals. In Skrjabin KI ed, Essentials of Cestodology, Vol. 1. The Academy of Sciences of the USSR, Moscow. Translated from Russian for the U.S. National Science Foundation and Department of Commerce, Washington DC. 1951, p 783.

9. Yamaguti S. Studies on the helminth fauna of Japan. Part 42. Cestodes of mammals II. Kyoto, Japan. 1942, pp 1-18.

10. Riggenbach E. Taenia dendritica Goeze. Zbl Bakt Mik Hyg I C 1895; 17: 710-716 (in Germany).

11. Kim MH, Lee HP, Noh YT. Study on laelaptid mites parasitic from rodents in Korea (Acari; Mesostigmata). Korean Arachnol 1986; 2: 55-61.

12. Lee WK. Illustrated Encyclopedia of Fauna \& Flora of Korea. Vol. 44. Acari: Anactinotrichida. Seoul, Korea. Ministry of Education, Science and Technology. 2009, p 284.

13. Uchikawa K. Studies on mesostigmatid mites parasitic on mammals and birds in Japan. III. On the identity of Hirstionyssus apodemi Zuevsky, 1970, with H. sunci Wang, 1962, and the description of Hirstionyssus japonicas spec. nov. (Mesostigmata: Laelapidae). Jpn J Sanit Zool 1975; 26: 89-92.

14. Mašán $P$, Fenda $P$. A review of the laelapid mites associated with terrestrial mammals in Slovakia, with a key to the European species. Bratislava, USSR. Institute of Zoology, Slovak Academy of Sciences. 2010, p 187.

15. Hirst S. On some new parasitic mites. Proc Zool Soc London 1921; 91: 769-802.

16. Cyprich D, Lukáš J, Fenda P, Krumpál M. Ektoparazity (Mesostigmata, Ixodidae, Anoplura, Siphonaptera) veverice stromovej (Sciurus vulgaris Linnaeus, 1758) a jej hniezdz územia Slovenska. Folia Faunistica Slovaca 1999; 4: 65-74.

17. Ree HI. Fauna and key to the chigger mites of Korea (Acarina: Trombiculidae and Leeuwenhoekiidae). Korean J Syst Zool 1990; 6: 57-70.

18. Lee IY, Kim HC, Lee YS, Seo JH, Lim JW, Yong TS, Klein TA, Lee WJ. Geographical distribution and relative abundance of vectors of scrub typhus in the Republic of Korea. Korean J Parasitol 2009; 
47: 381-386.

19. Kim HC, Lee IY, Chong ST, Richards AL, Gu SH, Song JW, Lee JS, Klein TA. Serosurveillance of scrub typhus in small mammals collected from military training sites near the DMZ, northern Gyeonggi Province, Korea, and analysis of the relative abundance of chiggers from mammals examined. Korean J Parasitol 2010; 48: 237-243.

20. Lee IY, Song HJ, Choi YJ, Shin SH, Choi MK, Kwon SH, Shin EH, Park C, Kim HC, Klein TA, Park KH, Jang WJ. Larval chigger mites collected from small mammals in 3 provinces, Korea. Korean J Parasitol 2014; 52: 225-229.

21. Rhee HI, Cho MK, Lee IY, Jeon SH. Comparative epidemiological studies on vector/reservoir animals of tsutsugamushi disease between high and low endemic areas in Korea. Korean J Parasitol 1995; 33: 27-36.

22. Asanuma K. Chiggers found on a squirrel, Sciurus vulgaris lis, in Japan. Jpn J Sanit Zool 1957; 8: 181-182.

23. Rothschild NC. New Siphonaptera. Proc Zool Soc London 1908: 617-629.

24. Brinck-Lindroth G, Smit FGAM. The fleas (Siphonaptera) of Fennoscandia and Denmark. Fauna Entomologica Scandinavica Vol. 41. Brill, Leiden. 2007, p 196.

25. Jordan K. Suctoria--Fleas. In Smart J, Jordan K, Whittick RJ eds, A
Handbook for Identification of Insects of Medical Importance. 4th ed. London, UK. Trustees of the British Museum (Natural History). 1965, p 211.

26. Chung SL, Hwang SJ, Kwon SB, Kim DW, Jun JB, Cho BK. Outbreak of rat mite dermatitis in medical students. Int J Dermatol 1998; 37: 591-594.

27. Rhee HI, Lee IY, Cho MK. Determination of the vector species of tsutsugamushi disease in Korea. Korean J Parasitol 1991; 29: 8792.

28. Feliu C, Torres J, Miquel J, Casanova JC. The helminth faunas of rodents of the Iberian Peninsula in relation to continental rodents: The case of Sciurus vulgaris Linnaeus, 1758 (Sciuridae). Res Rev Parasitol 1994; 54: 125-127.

29. Shimalov VV, Shimalov VT. Helminth fauna of the red squirrel (Sciurus vulgaris Linnaeus, 1758) in Belorussian Polesie. Parasitol Res 2002; 88: 1008.

30. Romeo C, Pisanu B, Ferrari N, Basset F, Tillon L, Wauters LA, Martinoli A, Saino N, Chapuis JL. Macroparasite community of the Eurasian red squirrel (Sciurus vulgaris): poor species richness and diversity. Parasitol Res 2013; 112: 3527-3536.

31. Wauters LA, Dhondt AA. Activity budget and foraging behavior of the red squirrel (Sciurus vulgaris, Linnaeus, 1758) in a coniferous habitat. Mamm Biol 1987; 52: 341-352. 